\title{
0 PAPEL DA SUBJETIVIDADE NOS PROCESSOS COGNITIVOS DE CRIANÇAS DAS SÉRIES INICIAIS DO ENSINO FUNDAMENTAL DE 9 ANOS ${ }^{1}$
}

\section{THE ROLE OF SUBJECTIVITY IN COGNITIVE PROCESSES OF CHILDREN FROM EARLY 9-YEAR ELEMENTARY SCHOOL}

\section{EL PAPEL DE LA SUBJETIVIDAD EN LOS PROCESOS COGNITIVOS DE NIÑOS EN SERIES INCIALES DE LA EDUCACIÓN BÁSICA DE 9 AÑOS}

\author{
Thomas Massao Fairchild* \\ Alana Clemente Lima* \\ Belly Elimy Tavares Honório
}

\begin{abstract}
Resumo: O presente artigo apresenta resultados preliminares do projeto " $\mathrm{O}$ desafio de ensinar a leitura e a escrita no contexto do Ensino Fundamental de 9 anos e da inserção do laptop na escola pública brasileira”, produzidos pela equipe sediada em Belém/PA. Tem por objetivo discutir a relação entre os sujeitos psíquico e cognoscente em processos de alfabetização. O trabalho é focado na análise do desempenho de duas crianças das séries iniciais do EF/9, documentado por meio de um diário de campo e instrumentos de diagnóstico elaborados pela equipe. As análises mostram que as posições assumidas pela criança na relação com professores e colegas podem conduzir à elaboração de resistências que as levam a evitar as tarefas propostas e, consequentemente, têm um impacto direto no desenvolvimento das competências verificadas por meio de instrumentos objetivos de diagnóstico.
\end{abstract}

Palavras-chave: Alfabetização. Sujeito Psíquico. Sujeito Cognitivo.

\begin{abstract}
This paper presents preliminary results of the project "The challenge of teaching reading and writing in the context of the 9-year elementary school and the insertion of laptops in Brazilian public schools, achieved by the team based in Belém, Pará. It aims to discuss the relation between psychic subject and cognitive subject in processes of early literacy. The work focuses on the analysis of the performance of two children, both from the initial years of EF/9, documented through field logs and instruments of diagnosis developed by the team. The analysis show that the subjective positions taken by the children in their relationship with teachers and peers may lead to the development of resistances that cause them to avoid the proposed tasks and thus have a direct impact on skills assessed by objective instruments of diagnosis.
\end{abstract}

Keywords: Literacy. Psychic Subject. Cognitive Subject.

\footnotetext{
${ }^{1}$ Trabalho vinculado ao projeto "O desafio de ensinar a leitura e a escrita no contexto do Ensino Fundamental de 9 anos e da inserção do laptop na escola pública brasileira", financiado por meio do edital nº 38/2010/CAPES/ INEP - Observatório da Educação, e realizado em conjunto com equipes sediadas na Universidade Estadual do Rio Grande do Norte (UERN) e na Universidade de São Paulo (USP), sob a coordenação geral de Claudemir Belintane.

* Doutor em Educação da Universidade Federal do Pará. E-mail: tmfairch@yahoo.com.br

** Graduanda em Letras da Universidade Federal do Pará. E-mail: lana_hits@hotmail.com

*** Graduanda em Letras da Universidade Federal do Pará. E-mail: bellyhonorio1@hotmail.com
} 
Resumen: En el presente trabajo se presentan los resultados preliminares del proyecto "El reto de la enseñanza de la lectura y escritura en el contexto de la educación básica de 9 años y la inserción de la computadora portátil en las escuelas públicas de Brasil”, producido por el equipo con sede en Belém, Brasil. Su objetivo es analizar la relación entre los procesos psíquicos y cognoscente en el proceso de alfabetización. El trabajo se centra en el análisis del rendimiento de dos niños de la serie inicial de EB/9, documentado a través de un diario de campo y las herramientas de diagnóstico desarrollados por el equipo. Los análisis muestran que las posiciones adoptadas por el niño en la relación con los profesores y los compañeros pueden llevar al desarrollo de resistencias que lo lleva a evitar las tareas propuestas y, por lo tanto, tienen un impacto directo en el desarrollo de habilidades comprobadas por las herramientas objetivas de diagnóstico.

Palabras clave: Alfabetización. Sujeto psíquico. Sujeto cognitivo.

\section{Introdução}

A criança que tarda em se alfabetizar é uma figura emblemática na escola brasileira. Dificuldades relacionadas ao "ritmo de aprendizagem” e ao tempo de alfabetização exercem enorme pressão sobre os professores das séries iniciais, inculcam temores em pais e familiares e, há muitas décadas, são alvo de medidas governamentais que tentam ajustar o desempenho das crianças a um fluxo escolar esperado - um exemplo recente é a criação do "Pacto pela Alfabetização na Idade Certa”. A expectativa de que certos níveis de aprendizagem sejam atingidos dentro de certo período exerce influências variadas, sobretudo, no próprio percurso escolar das crianças.

O presente trabalho ${ }^{2}$ coloca este problema em discussão, abordando a variedade de percursos que o sujeito pode traçar na aquisição da escrita. Essa perspectiva se contrapõe à noção de que a aprendizagem da leitura e da escrita se daria em um percurso

\footnotetext{
${ }^{2}$ Os dados apresentados aqui são produto da operação da equipe que atua na Escola de Aplicação da UFPA, que atualmente acompanha as turmas de $1^{\circ}$ e $2^{\circ}$ ano do Ensino Fundamental de nove anos (EF/9). A equipe envolve alunos do Programa de Pós-graduação em Letras, alunos de graduação em Letras e Pedagogia e professores da escola.
}

linear, divido em níveis sucedâneos uns aos outros - uma noção que tem forte esteio na história da alfabetização no Brasil, presente desde os Testes ABC, de Lourenço Filho, até a mixórdia dos métodos alfabético, fônico, silábico, misto, global etc. (MORTATTI, 2000, 2006; BELINTANE, 2006), sem excluir a perspectiva construtivista baseada nos trabalhos de Ferreiro e Teberosky (1985). Acreditamos que a impressão de que alguns alunos não seguem o ritmo, antes de ser uma questão que diga respeito unicamente à peculiaridade da própria criança, parece ser resultado também da ausência de recursos que permitam vê-la de outras maneiras - isto é, da ausência de modelos teóricos, instrumentos de diagnóstico e estratégias pedagógicas que deem conta da articulação entre os elementos de um currículo universal e as apropriações singulares da criança.

Em contraposição, o projeto em que este trabalho se insere pressupõe que os processos de alfabetização não são redutíveis a uma escala única, mas envolvem um conjunto de operações cognitivas e modulações subjetivas que podem se desenvolver de forma simultânea e não necessariamente em movimentos escalares. Dessa forma, trabalha-se com a ideia de que o sujeito pode se situar concomitantemente em diversos 
pontos de uma escala, ou que há, pelo menos, uma série de eixos diferentes em que o sujeito pode ser avaliado sem que os resultados possam ser somados a fim de reduzir seu desempenho a um único coeficiente. Essa variedade de "eixos" nos quais o sujeito trabalha ao se apropriar da escrita também não consiste em uma série paralela de "escalas de evolução”, mas forma uma rede na qual o sujeito se movimenta de forma intervalar.

Assim, a questão do aluno "fora de ritmo" se mostra um quadro mais complexo do que uma questão de dificuldades individuais do aluno ou fragilidades do sistema de ensino. O projeto se preocupa especialmente com o fato de que as crianças eventualmente se deparam com dificuldades bastante específicas - singulares - em seu trato com a escrita, mas que, quando tratadas simplesmente como uma dificuldade de transpor um "nível”, tendem a ficar sem um atendimento específico e podem se manter estacionadas em um mesmo patamar de avaliação, sem que se consiga produzir outras informações relevantes a respeito dos obstáculos que ela enfrenta.

Pretendemos neste trabalho desenvolver algumas reflexões sobre um aspecto dessa complexidade: o jogo constante entre os impasses que a criança encontra diante de certas questões de ordem "cognitiva” operações como análise de palavras em segmentos menores, permuta de elementos não significativos da língua, associações entre elementos significativos de textos diferentes etc.- e a maneira como a criança vai se constituindo enquanto "sujeito da alfabetização" nos discursos da escola. Em outras palavras, trata-se de discutir as relações entre o que se poderia chamar de "sujeito cognitivo" - que, em geral, é o sujeito das avaliações institucionais, no nível da escola ou da gestão do sistema educacional - e um "sujeito psíquico” - sempre inscrito nas relações de ensino em sala de aula, ainda que, do ponto de vista institucional, possa ser descartado como "vestígio".

O artigo está dividido em quatro partes. Na primeira, trataremos de algumas premissas do projeto que embasam a elaboração das atividades e dos instrumentos de registro e diagnóstico utilizados na pesquisa, a saber:

a) a fita de Moebius como modelo de articulação não dicotômica entre oralidade $\mathrm{e}$ escrita;

b) o papel dos textos orais da infância na constituição de uma escrita latente, anterior à escrita alfabética;

c) o rébus como operação articuladora da letra.

Na segunda e terceira partes, colocaremos em foco os conceitos de sujeito psíquico e cognoscente, relacionando-os com as ações de ensino, registro e diagnóstico do projeto. Por fim, na última parte apresentaremos dados retirados dos diários de campo e dos instrumentos de diagnóstico referentes a duas turmas do Ensino Fundamental de nove anos, uma de $1^{\circ}$ e outra de $2^{\circ}$ ano. A partir desses dados, ilustraremos a forma como se manifestam na prática, e simultaneamente, um sujeito psíquico e um sujeito cognitivo. As análises mostram que a constituição de ambos os sujeitos é pertinente para o processo de alfabetização e que eles exercem influências mútuas, requerendo a construção de instrumentos e técnicas que permitam ao professor alternar suas estratégias e, assim, auxiliar a criança a contornar as resistências singulares que esta produz diante das dificuldades encontradas, tanto na elaboração de conceitos e hipóteses sobre a escrita quanto em sua relação desejante com o Outro. 


\section{Apostas na alfabetização: algumas premissas do projeto abrangente}

Uma das premissas fundamentais do projeto no qual este trabalho se insere é a da existência de uma relação não dicotômica entre oralidade e escrita, ilustrada pela fita de Moebius (Figura 1). Imaginemos que cada face da banda corresponde a uma modalidade da linguagem: a estrutura da banda mostra que entre elas há um movimento cíclico, de modo que o sujeito pode passar da oralidade para a escrita e vice-versa, sem necessariamente transpor uma borda. Assim temos a noção de que, embora distintas, oralidade e escrita são indissolúveis, "reversíveis" - em geral se pensa apenas no movimento da oralidade para a escrita, mas não no inverso - $\mathrm{e}$ estão parcialmente contidas uma na outra.

Figura 1 - Fita de Moebius

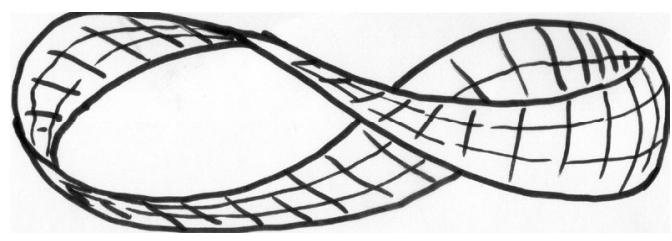

Fonte: $\mathrm{O}$ autor

Um dos desdobramentos concretos dessa concepção é a ênfase conferida nas atividades do projeto à investigação e desenvolvimento da oralidade dos alunos. Por um lado, esse posicionamento procura complementar as práticas e instrumentos de avaliação ou de "diagnóstico" baseados no modelo construtivista, que designa um "nível de conhecimento" para cada aluno com base em seu desempenho na escrita de palavras ou frases - desconsiderando, assim, as diferenças que pode haver no desempenho oral das crianças e suas habilidades específicas de leitura -; por outro lado, o projeto tem proposto uma série de atividades que pretendem avaliar e desenvolver certas operações realizadas na fala que estão diretamente ligadas ao ingresso do sujeito na escrita.

O primeiro conjunto de atividades voltadas a este segundo fim envolve o trabalho com textos e jogos orais como parlendas, trava-línguas, a "língua do pê", adivinhas, contos cumulativos, lendas, contos de fadas, fábulas etc. (BELINTANE, 2008). Trata-se de textos com forte presença do lúdico, que brincam com as palavras e contêm um tratamento poético da linguagem. Nosso entendimento é que textos como esses movimentam certos traços da língua e certas operações de linguagem que aproximam as crianças da escrita, estimulando e exigindo um trabalho de análise/síntese, permuta, expansão da memória etc. Assim, por exemplo, o jogo da "língua do pê" exige a segmentação de palavras, frases ou enunciados inteiros em pés silábicos - condição para que a criança chegue, ao menos, a uma escrita silábica. Daí se pode tirar uma correlação que até o momento vem sendo verificada com bastante consistência: crianças que não conseguem jogar a "língua do pê" (não entendem a brincadeira, "chutam" ou tentam adivinhar etc.) são crianças que se encontram em um estágio pré-silábico de escrita; porém, o contrário não ocorre. Portanto, se presumirmos que aprender a codificar e decodificar mensagens na "língua do pê" pode ser uma condição que favorece a "fonetização da escrita", diremos que:

a) há uma escrita latente no jogo de falar a "língua do pê";

b) esta escrita latente não depende do conhecimento do alfabeto para se desenvolver;

c) entre crianças não alfabetizadas essa escrita pode ou não estar desenvolvida.

Assim, teremos uma ilustração bastante concreta do tipo de relação complexa que supomos haver entre oralidade e escrita. 
O segundo conjunto de atividades utilizadas com sistematicidade se fundamenta no princípio non verbis sed rebus, que consiste em uma forma de escrita "com coisas, não com palavras” - reconhecidamente, uma das "descobertas" cruciais para a invenção da escrita (FEVRIER, 1948; GELB, 1982; POMMIER, 1993; ALLOUCH, 1995). Nestas atividades, são utilizadas diversas figuras que devem ser "lidas" pelas crianças apenas conforme a sonoridade de seus "nomes”, de forma que a junção dos nomes ou partes dos nomes de duas ou mais figuras forme uma nova palavra. Assim, por exemplo, pode-se alinhar as figuras de uma galinha e de um tomate e, utilizando-se o princípio da acrofonia (considerar apenas a primeira sílaba), obter a palavra "gato”. Atividades baseadas neste princípio envolvem uma forma de leitura, ainda que não utilizem o alfabeto, uma vez que as imagens utilizadas no rébus não são tomadas como tendo um valor de representação pictórica, mas de representação sonora - trata-se, portanto, de utilizar imagens como letras, elaborando uma espécie de alfabeto ad hoc. Mais do que isso, trata-se de um tipo de leitura que pode ser realizado por crianças não alfabetizadas.

Este tipo de exercício permite à criança começar a lidar com os suportes gráficos da escrita sem necessariamente ter de se apropriar do repertório amplo e sutil das vinte e seis letras do nosso alfabeto, em suas versões de forma e cursiva, maiúscula e minúscula, acrescidas de todas as variações e misturas normalmente encontradas nas escritas com que nos deparamos no dia a dia - incluindo as idiossincrasias da escrita dos professores que alfabetizam, de pais e irmãos que tentam ajudar etc. Ensaiar a leitura e a escrita a partir do alfabeto, com efeito, muitas vezes significa se deparar ao mesmo tempo com uma série de questões muito variadas - memorização e reconhecimento da forma gráfica das letras, dos seus nomes e "valores sonoros"; análise da língua falada e segmentação em elementos discretos; compreensão da letra como elemento de um sistema de representação; irregularidades relacionadas a aspectos específicos da língua, como a grafia das vogais e ditongos nasais, dígrafos etc. O que se tem constatado é que, dependendo do quanto algumas dessas questões estejam resolvidas para cada criança, mais facilidade ou resistência ela terá ao lidar com a tarefa de escrever alfabeticamente. Em especial, temos percebido que uma boa quantidade de crianças no $1^{\circ}$ e $2^{\circ}$ anos do EF/9, mesmo tendo desenvolvido certas "estratégias de sobrevivência escolar” - memorização da grafia de um conjunto às vezes bem amplo de palavras; conhecimento do alfabeto; boa caligrafia; ou, de outro lado, estratégias mais rasteiras para copiar as respostas dos colegas, seduzir o professor para que o auxilie com soletração etc. - e durante algum tempo se passando por crianças que "já leem e escrevem”, mostram dificuldade de avançar além desse ponto.

O princípio do rébus envolve, portanto, um conjunto de operações que isolam o funcionamento da escrita enquanto operação de representação gráfica da língua falada de todas as outras questões convencionais envolvidas com a apropriação do alfabeto. Trata-se, em certo sentido, de uma "escrita sem sistema”, que exige de cada gesto de leitura ou escrita:

a) nomear certo conjunto de imagens;

b) descartar o significado das imagens;

c) destacar do nome do objeto representado determinada sílaba; ${ }^{3}$

\footnotetext{
3 Tem-se trabalhado, na maior parte das vezes, com rébus acrofônicos, em que as imagens são utilizadas para representar apenas a sílaba inicial da palavra. Em alguns casos, utilizamos “diacríticos” para sinalizar
} 
d) reunir, na ordem dos desenhos, as sílabas destacadas de seus nomes;

e) formar uma nova palavra, que nada tem a ver com o significado de nenhuma das imagens utilizadas em sua representação.

Os exercícios realizados com as crianças nos dados apresentados no item 5 envolvem atividades baseadas nesses princípios. Antes de passar à análise desses dados, em todo caso, faremos algumas considerações sobre as noções de sujeito cognoscente e sujeito psíquico que mobilizaremos em nossas discussões.

\section{Sujeito cognoscente}

A noção de sujeito cognoscente que consideramos neste trabalho é aquela que deriva dos estudos de Piaget e, em especial, dos trabalhos de Ferreiro e Teberosky (1985) e Ferreiro (1985) sobre alfabetização. Segundo a teoria de Piaget, o desenvolvimento cognitivo acontece por "assimilação" e “acomodação”, dois processos que tendem ao equilíbrio (MOREIRA, 1999). No processo de assimilação, o sujeito incorpora um novo objeto a um esquema já construído, sem que isso implique modificar o esquema. Se o contrário acontecer, deparamo-nos com a acomodação, que se dá quando o objeto requer uma modificação nos esquemas de que o sujeito dispõe, levando-o a construir novos processos de assimilação. O jogo entre esses dois processos resulta no desenvolvimento cognitivo, isto é, na ampliação e complexificação dos esquemas de pensamento. Dentro dessa perspectiva, o sujeito é considerado

que a sílaba alvo não é a primeira - colocando-se ao lado da figura o número correspondente à posição da sílaba na palavra. Esta é, a propósito, uma operação necessária para produzir rébus em português, já que se trata de uma língua em que certas sílabas não ocorrem em posição inicial. um “sujeito cognoscente”, ou seja, um sujeito que realiza ações sobre os objetos do mundo e a partir deles constrói esquemas mentais.

A transposição mais frequente dessa noção para o campo específico da alfabetização se dá pelo intermédio do trabalho de Ferreiro e Teberosky (1985). Baseadas na epistemologia genética de Piaget, elas propõem que, no processo de aquisição da escrita, a criança elabora hipóteses diversas, em alguma medida imprevisíveis, mas que perfazem um caminho pelo qual todo sujeito necessariamente passaria. Essas hipóteses geralmente são agrupadas em "estágios” nomeados como pré-silábico, silábico, silábico-alfabético e alfabético. O nível pré-silábico refere-se a um amplo espectro de hipóteses que têm em comum o fato de a criança ainda não considerar a letra como elemento que representa a língua falada; por este motivo, para "escrever" ou representar uma determinada palavra ou frase, ela geralmente se utiliza de desenhos ou garranchos que imitam o aspecto visual da escrita. Quando já conhece algumas letras do alfabeto, é possível que ela escreva uma sequência sem que as letras sejam utilizadas de acordo com sua função convencional, mas, ainda assim, a criança pode elaborar suas próprias “convenções” na forma de regras como "não repetir a mesma letra na mesma palavra” etc. As escritas silábicas consistem nas formas de escrita em que a criança desvincula o objeto da palavra escrita, o que lhe permite representar cada sílaba com uma letra, às vezes utilizando só vogais ou só consoantes, de acordo com seu "valor sonoro" ou não. As escritas silábico-alfabéticas são aquelas em que a criança insere algumas sílabas completas sem ter abandonado totalmente o princípio silábico de representação, produzindo grafias como "PICZA", por exemplo, para representar "princesa” etc. Por fim, o nível 
alfabético representa o momento em que a criança compreende a articulação interna da sílaba em vogais e consoantes, embora isto também abarque vários tipos de desempenho (domínio das sílabas complexas, encontros consonantais, dígrafos, convenções relacionadas a grafias etimológicas etc.), razão pela qual algumas escolas cunham o termo "alfabético-ortográfico” para se referir ao "último estágio” da escrita.

Dentro dessa perspectiva, se o conhecimento é construído através de experiências e aprender requer um processo ativo no qual os esquemas de pensamento se constroem a partir da ação sobre o meio, não se pode reduzir a criança a um par de olhos e ouvidos que apenas colabora como um indivíduo passivo no processo da alfabetização (FERREIRO, 1985). Muito pelo contrário, há nessa criança um "sujeito cognoscente" que utiliza suas experiências para questionar, pensar, construir e reconstruir o que lhe está sendo posto. Para tanto, esse sujeito, que tem autonomia em seu processo cognitivo, não depende totalmente de um adulto que lhe repasse todo o conhecimento que é necessário para se apropriar da língua escrita, nem é capaz de assimilar esse conhecimento de uma só vez, dependendo dos esquemas que já construiu; em vez disso, ele tenta resolver seus questionamentos procurando seus próprios meios para encontrar uma solução. É exatamente o que faz quando cria para si, por exemplo, segundo Ferreiro, critérios para selecionar as letras que utilizará para grafar uma determinada palavra, estabelecendo parâmetros no eixo de quantidade ou no eixo qualitativo, como no exemplo abaixo:

Gustavo (6 $\left.6^{\mathrm{a}} \mathrm{CM}\right)$ exige pelo menos três caracteres [para escrever uma palavra] e justifica dizendo que o grupo das que não servem para ler é porque "têm uma palavra ou duas, enquanto que as outras têm muitas, como quatro". (Ele usa "palavra” no lugar de "letra” ou "caracteres gráficos”) (FERREIRO; TEBEROSKY, 1985, p. 45).

Portanto, um dos pontos interessantes da teoria de Ferreiro é mostrar que a criança aprende a escrever de certas maneiras que não lhe foram ensinadas, mas foram criadas por ela mesma. Por outro lado, como já mencionamos acima, a perspectiva construtivista baseada nas pesquisas de Ferreiro e seus colaboradores tem considerado a aquisição da escrita unicamente do ponto de vista das hipóteses construídas pela criança em relação à grafia de palavras - quase sempre nomes, isto é, substantivos e adjetivos -, em um nível intravocabular. Duas extrapolações nos parecem necessárias em relação a este modelo. A primeira delas, conforme já dissemos, consiste em considerar que, no processo de alfabetização, a criança não lida unicamente com "a escrita" enquanto objeto de conhecimento - além disso, ela precisa realizar operações e construir “esquemas” a respeito da própria língua falada (de que maneiras ela pode ser divida em segmentos discretos, quais os efeitos de diferentes combinações desses segmentos etc.) e da organização textual-discursiva dos textos (sejam orais ou escritos). Isso requer supor, correlatamente, que o repertório formado pela criança a partir de sua atividade linguística não consiste unicamente em uma coleção de sílabas, fonemas e letras combináveis, mas em um conjunto bem mais complexo de textos e parâmetros discursivos que formam uma rede mais aberta e menos cartesianamente organizável do que os diagnósticos de base estritamente construtivista fazem crer.

A segunda extrapolação ao diagnóstico construtivista nos leva ao próximo item. 


\section{Sujeito psíquico}

Uma segunda extrapolação necessária em relação ao sujeito cognoscente da epistemologia genética diz respeito ao fato de que, em seus processos de desenvolvimento, o sujeito não interage apenas com "objetos" apresentados em seu meio - como as varetas de tamanhos variados dos experimentos de Piaget -, mas também interage com outros sujeitos, em relação aos quais precisa construir certas hipóteses, “esquemas” e formas de ação. No caso específico da alfabetização, essa perspectiva nos parece ainda mais necessária, uma vez que a escrita não existe como objeto em si - ela só se constitui como objeto na medida em que é apresentado como tal pelo outro.

Com o termo "sujeito psíquico”, queremos acrescentar à dimensão “cognitiva” da aprendizagem uma ordem de questões que diz respeito à maneira como, em seu trabalho intelectivo sobre os "objetos de conhecimento”, o sujeito inevitavelmente se enreda em uma atividade que inclui seu próximo. A expressão remete à psicanálise - perspectiva segundo a qual, em grandes linhas, o ser humano se constitui como sujeito a partir das relações "sociais” que estabelece ao longo da vida, especialmente as relações mais precoces com os membros da família ou com quem quer que exerça papel semelhante. $\mathrm{O}$ "sujeito psíquico", na teoria psicanalítica, caracteriza-se pelo desejo que, por sua vez, surge por meio da falta. Essa falta de que trata a psicanálise é instaurada pela impossibilidade de se regressar ao estado de satisfação plena da vida intrauterina, e permanece ao longo da vida na forma daquilo que Lacan chamou de “objeto a” (NASIO, 1993). Tratase, grosso modo, da falta decorrente do interdito edípico (a suposição de que o “pai” é aquele ser humano que detém a resposta para o desejo da “mãe” e, por isso, se interpõe na relação direta entre “mãe” e "filho”), ou ainda, da impossibilidade de tudo se representar pela linguagem, visto que há um "real” que não se deixa representar ou que, ao ser dito, deixa de ser o que era - como os sintomas amplamente registrados na literatura clínica. O desejo resulta, por conseguinte, do movimento pelo qual o sujeito procura constituir para si "objetos substitutivos" que reponham essa falta, em última instância, irreparável.

Na maioria das vezes, a escola desconsidera a importância deste sujeito desejante, tratando o aluno como um indivíduo generalizado, deixando de lado sua subjetividade e consequentemente achatando-o em tentativas de compreender os processos de aprendizagem como se estes fossem padronizáveis. Uma das justificativas disso é justamente o "sujeito cognoscente": toda criança seria, em princípio, o mesmo sujeito cognoscente, isto é, um sujeito em condições iguais de se defrontar e agir sobre o objeto de conhecimento. Passam pelos mesmos “estágios”, na mesma ordem, realizam as mesmas operações e constroem, ao fim e ao cabo, os mesmos conceitos. Em geral, o que não diz respeito à relação do sujeito cognoscente com o objeto de conhecimento é considerado "resíduo". Nosso ponto de vista é que esse "resíduo" consiste em uma parte importante dos processos de ensino e aprendizagem, pois sempre está presente e determina, inclusive, em que condições a criança realiza seu trabalho “intelectual” propriamente dito. Neste ponto concentra-se um dos maiores desafios do projeto: trazer à tona a subjetividade do aluno, focando as tensões geradas pelas relações entre a criança e o outro - podendo ser este "outro", no âmbito escolar, o professor, os colegas, a própria escola, a escrita - e, finalmente, tirando consequências das elaborações singulares da criança (aquelas para as quais não há uma escala de "níveis” previamente estabelecida para classificá-las). 
Em um trabalho bem difundido, Smolka (2004) apresenta uma discussão a respeito das relações subjetivas em sala de aula. Embora sua base teórica não inclua a psicanálise, a noção de subjetividade mobilizada por ela é semelhante à noção de "sujeito psíquico” com que trabalhamos. A autora afirma que

todo o processo discursivo supõe da parte do emissor, uma antecipação das representações do receptor, isto é, sua habilidade de imaginar, de pensar onde seu ouvinte o "enquadra”, e que esta antecipação de "o que o outro vai pensar" do lugar em que ele se representa como tal parece constitutiva de todo discurso. (SMOLKA, 2004, p.30).

Neste trecho, destaca-se que nas interações mencionadas aparecem as "imagens do outro", isto é, tudo aquilo que o "eu” supõe acerca da compreensão de seu ouvinte em relação ao seu próprio discurso. Retomando uma noção geral da psicanálise, acrescentamos que parte dessas imagens são inconscientes, pois não estão acessíveis à inteligência dos sujeitos do discurso, mas constituem cada sujeito psíquico em sua forma de "enxergar" o outro.

Inserindo esta relação discursiva no âmbito escolar, Smolka (2004) elabora uma distinção entre dois conceitos: relação de ensino e tarefa de ensinar. Para a autora, a tarefa de ensinar é imposta socialmente como profissão ou missão: trata-se do aspecto imaginário da relação entre professor e aluno aquilo que se imagina estar fazendo quando se ensina determinado assunto, aquilo que se imagina que o aluno aprendeu quando se colhe determinada resposta mais ou menos condizente com uma expectativa prévia. A relação de ensino, por outro lado, consiste no aspecto mais difícil de recuperar das interações em sala de aula, isto é, aquilo que diz respeito às “imagens” inconscientes que delineiam as posições sucessivamente assumidas pelos sujeitos em relação uns aos outros. Para Smolka, a tarefa de ensinar pode se basear na relação de ensino, no entanto, muitas vezes acaba por ocultá-la.

A autora apresenta algumas situações práticas de salas de alfabetização nas quais a interação discursiva entre professor e aluno revela como se dá a relação de ensino estabelecida entre eles, dentre as quais a seguinte:

De frente para a lousa e de costas para as crianças, a professora pergunta:

- Se eu puser isso (aponta bo) aqui (na frente do né), como é que fica?

Uma criança fala: — boneca.

A professora pergunta, virando-se para as crianças:

— Quem falou boneca?

Ninguém responde. [...]

A professora passa pelas fileiras vendo os cadernos de carteira em carteira:

Prof. para S4: - Tem que fazer. Você não deixou espaço. Olha lá. Eu deixei espaço lá.

Para S5: - Esse aqui é bo. Tá errado, tá errado. Olha bem lá! Já copiou errado.

Para S6: - Aqui a senhora nem colocou. Fez tudo misturado. Nem colocou nem fez. Tá tudo malfeito. Tem que fazer benfeito [...]. (SMOLKA, 2004, p. 33-34).

O que Smolka mostra com este exemplo é que há um ciclo no qual há uma pressuposição por parte da professora e uma resposta por parte dos alunos. A professora solicita algo dos alunos esperando que eles o façam de determinada forma, no entanto, ela mesma não explica de que forma devem fazer o que solicitou. A professora imagina que 
está explicando como formar palavras pela junção de sílabas (isto é, cumpre uma "tarefa de ensinar”), mas concretamente instaura uma relação de ensino em que as respostas corretas são exigidas sem que se ensine de fato como fazê-lo. Para os alunos, fica a ideia de que eles têm de fazer o que a professora quer e que isto é aprender, assim como a professora acredita que está ensinando no momento em que diz "copiem estas palavras no caderno”, por exemplo. O problema inscrito neste ciclo consiste no fato de que nem sempre as pressuposições da professora coincidem com a resposta real dos alunos para a atividade, causando dúvida e decepção na professora, que acaba por transmitir a responsabilidade aos alunos, vistos como aqueles que não sabem, não aprendem. Os alunos, por sua vez, colocam-se na posição de não saber quando percebem que não correspondem à expectativa da professora.

O que se pode acrescentar em relação à discussão de Smolka é que, para as crianças, "não saber” pode se tornar uma posição cômoda, ainda que gere certo desconforto, passando a ser uma solução viável quando se defrontam com um desafio para o qual não dispõem de ferramentas para resolver e podem contar com a disposição da escola para aceitar sua incapacidade como um fato esperado.

A este descompasso entre tarefa de ensinar e relação de ensino, Smolka dá o nome de ilusão, que seria justamente quando o professor acha que está ensinando e fazendo o seu trabalho, porém o aluno não está aprendendo, ou quando o professor acredita que o aluno só aprende no momento em que ele ensina. Esta ilusão está relacionada à crença de que tudo que é ensinado pelo professor estaria implícito em sua tarefa, fazendo que este não considere fatores como a própria relação de ensino e, assim, deixe de lado o pensamento crítico acerca de sua função como professor. “A sua ilusão acaba sendo efeito de sua posição no sistema de representações sociais” (SMOLKA, 2004, p. 32. Grifos da autora).

Voltando à psicanálise, situações como as descritas por Smolka colocam em jogo, a nosso ver, professor e aluno como sujeitos psíquicos, desejantes. Em outras palavras, estamos dizendo que a construção de “esquemas de pensamento" não depende apenas da iniciativa de um sujeito que age sobre os objetos que se lhe apresentam, mas também de uma aposta que o outro faz a seu respeito. Isso significa que a maneira como o professor enxerga e considera o aluno está relacionada, constitutivamente, com a maneira como o aluno é levado a se enxergar enquanto aluno, e pode dar-lhe melhores ou piores condições para desenvolver seu trabalho cognitivo propriamente dito. Um dos obstáculos que surgem a partir disso ocorre se o aluno percebe que, independentemente de suas tentativas de apreender o que lhe é posto como tarefa (mesmo que de forma malsucedida), sempre acabará sendo encaixado em um nível genérico de desempenho - por exemplo, no estereótipo do "aluno que não acompanha o ritmo da classe”. Nesse caso, cedo ou tarde é provável que ele desista de fazer seu papel de criança piagetiana e passe a se relacionar com o conhecimento escolar através da elaboração de "sintomas" (dos quais veremos alguns exemplos mais adiante) - último recurso de expressão singular. A partir do momento em que esse tipo de relação se instaura, é fácil passar a ter a sensação de que se está diante de um "sujeito cognoscente” diminuído em suas capacidades. 


\section{O cognitivo e o subjetivo na alfabetização}

As atividades realizadas na Escola de Aplicação da UFPA têm se dado conforme uma organização do trabalho em que cada turma é acompanhada por dois professores, sendo um deles o professor da escola e o outro, um aluno de graduação. A presença de dois professores em sala de aula facilita a condução das atividades gerais com a turma e, ao mesmo tempo, propicia um acompanhamento mais detalhado de cada aluno. Tem cabido aos segundos professores registrar o desempenho individual dos alunos por meio de diários de campo e da aplicação de instrumentos de diagnóstico. Por meio dessas ações tem-se conseguido depreender dados mais precisos sobre os alunos, especialmente aqueles que, dentro de um grupo, tendem a permanecer calados, responder apenas "em coro" com os colegas, fazer atividades com a ajuda dos outros etc. A avaliação do desempenho desses alunos, sem um acompanhamento mais próximo, pode apresentar dados falseados - eles podem aparentar seguir o ritmo da turma, mas em avaliações individuais mostram-se em maiores dificuldades - ou incompletos - pode-se passar muito tempo sem obter produções consistentes desses alunos, dependendo de como a turma é conduzida.

Os registros produzidos pelos participantes do projeto têm mostrado diversas situações de emergência da subjetividade dos alunos, o que tem permitido, por sua vez, elaborar tentativas de manejo das dificuldades singulares apresentadas pelas crianças. Nos dados apresentados a seguir, procuramos evidenciar o que se pode depreender do funcionamento imbricado de um "sujeito cognoscente" e de um "sujeito psíquico" e pontuamos algumas das estratégias pelas quais o projeto vem tentando dar conta dessa complexidade.

Tomamos como ponto de partida uma situação encontrada com frequência e que muitas vezes é o início de um trabalho mais específico de acompanhamento individual: a detecção de resistências elaboradas pelos alunos como forma de evitar o engajamento em questões de ordem "cognitiva". O exemplo a seguir, transcrito dos diários de campo do projeto, ilustra um desses casos. O dado se refere ao aluno G., de seis anos, da turma 1003 ( $1^{\circ}$ ano do EF/9). A tarefa proposta era de apanhar uma folha com várias sílabas e recortá-las, tentando juntar essas sílabas para formar palavras. $\mathrm{O}$ aluno G. realizou a atividade até o momento de recortar as sílabas; após ter feito isso, parou, e quando a segunda professora perguntou o porquê de ele ter parado, G. respondeu que não sabia.

(01) G., mesmo falando que não sabia, juntou o PA com o TA, e quando eu perguntei o que formava ele ficou olhando fixamente, e após alguns minutos respondeu: PATA. Quando eu perguntei o que era isso ele respondeu como algo óbvio: “É a mãe do patinho!”. Eu disse que ele tinha entendido e que era pra começar a fazer o resto. Quando me dirigi a ele após alguns minutos vi que tinha juntado todos os PAs e TAs, formando apenas a palavra pata. Deixei um dos pares intacto e misturei as outras sílabas com o resto, dizendo para ele tentar fazer outra palavra que não fosse essa. Ele se virou para o lado e disse que não sabia.

Na situação descrita acima, pode-se isolar com certa facilidade dois comportamentos distintos do aluno G. O primeiro deles é a afirmação de que não sabe realizar a tarefa; o segundo é o próprio início da realização da tarefa, na junção de duas sílabas para formar a palavra "PATA". Uma vez que, aparentemente, a formação da palavra foi 
uma descoberta feita no momento - G. passa algum tempo olhando para a palavra formada antes de lê-la -, pode-se supor que seu desempenho "cognitivo" efetivo, mensurável por meio de algum instrumento objetivo de avaliação, não coincide com suas próprias expectativas. Em outras palavras, o "não sei” de G. não parte de um conhecimento que ele supostamente teria de sua própria capacidade de resolver as tarefas da escola, mas de uma imagem produzida em outro lugar que não em seu trabalho sobre o "objeto de conhecimento”. Essa divisão, desconsiderada do ponto de vista da epistemologia genética, também não se resolve tão facilmente: após perceber-se capaz de formar uma palavra, o aluno G. parece continuar se atendo à hipótese de que não sabe resolver a atividade e procura formar, novamente, a mesma palavra várias vezes. Portanto, este pode ser um exemplo em que o desejo - isto é, o movimento do aluno em busca de reforçar o primeiro sucesso obtido na tarefa - se sobrepõe à empreitada mais lógica de procurar generalizar o primeiro procedimento na formação de novas palavras.

O próximo dado, semelhante ao anterior, é referente à aluna E., de seis anos, da turma 2002:

(02) [...] A aluna E. me chamou algumas vezes pedindo ajuda, dizendo que estava com dor de barriga e perguntando como fazia a atividade, mas quando eu perguntava o que era o desenho e quem formava cada pedacinho, ela respondia e escrevia”.

Neste excerto, a aluna E. está realizando uma tarefa que consiste em observar e identificar os desenhos de figuras que representam "lua”, “bola”, “bolo”, “novelo”, "luva”, “mala”, “vela”, "bala”, “sacola”, “leão”, “peixe” e “cavalo”, presentes em uma folha entregue pela professora, e em seguida escrever seus respectivos nomes ao lado de cada um. Observa-se que a aluna E. manifesta uma suposta dor para pedir que alguém diga a ela o que tem de fazer. Com essa “dor”, ela aparentemente busca algum argumento que a dispense de fazer a tarefa sozinha, apelando à segunda professora que, no momento, auxiliava-a a resolver as tarefas. O que destacamos neste excerto é que a segunda professora não responde ao apelo implícito na queixa de dor de barriga, mas responde à aluna com uma pergunta sobre a própria atividade, que ela, por sua vez, responde sem problemas; ou seja, neste momento a segunda professora pergunta o nome de cada desenho e a aluna E. mostra que sabe tanto nomeá-los quanto escrever seus nomes, o que faz logo depois - aparentemente a “dor” não era tão incômoda assim.

$\mathrm{O}$ que se percebe por meio desses excertos é que as relações de ensino são permeadas por elementos de outra ordem que não a da racionalidade implicada na resolução de tarefas aparentemente simples. Essas relações podem acabar condicionando o comportamento da criança e consequentemente do professor, o que influencia no processo de aquisição de escrita da criança. Neste caso, embora a criança demonstre ter capacidade para resolver a atividade que lhe foi proposta (nomear e escrever o nome de algumas figuras), ela se comporta inicialmente como se não soubesse fazê-lo. Em outras palavras, a criança deixa de lado parte do conhecimento que possui em troca da tentativa de ocupar uma posição que pode lhe conferir maior satisfação - a posição de incapacidade que lhe rende a aproximação de um adulto e a dispensa de encarar a tarefa "cognitiva” propriamente dita. Evidentemente, este movimento é realizado pela criança na forma de uma aposta ou, em outras palavras, na forma de uma hipótese que a criança lança sobre a maneira como supõe que o outro pode 
encará-la, e que o professor pode confirmar ou refutar - muitas vezes, sem se dar conta disso.

Como podemos imaginar, caso a segunda professora tivesse dado ouvidos à queixa de E. e partido em sua ajuda, provavelmente continuaríamos sem saber que E. de fato sabia como resolver a atividade. Assim, parece plausível supor que a criança pode apresentar desempenhos “cognitivos” diferentes conforme a posição que assume frente à própria demanda pela qual esse desempenho "cognitivo” será medido. A seguir, outro exemplo que demonstra esse tipo de situação, referente à aluna B., de seis anos, da turma 2002:

(03) [...] Enquanto os alunos começam a nomear as figuras, eu sento ao lado de B. Ela já havia escrito "bola”, "bolo” e "lua”, então ela me pede ajuda para escrever "novelo". Eu pergunto a ela qual a primeira sílaba, ela diz "no”. Quando eu peço para ela escrever a primeira sílaba ela fica repetindo "no, no, no". Eu pergunto que letras formam esse pedacinho; ela diz "O”; eu digo que há uma letrinha ao lado do "O" e pergunto qual é; ela novamente repete a sílaba várias vezes, em seguida diz que não sabe. Tento novamente perguntar qual a letra fazendo o som da letra "N" e pergunto que letra tem aquele som, ela diz novamente que não sabe. Eu falo junto com ela a família silábica da letra "N", e ela repete comigo: "na, ne, ni, no, nu”. Então eu pergunto: "N com $\mathrm{O}$ faz o que?”, e ela responde: “NO”, eu pergunto então o que ela deve colocar no primeiro pedaço de "novelo". Ela diz que não sabe e chora $[\ldots]$.

No exemplo acima, a aluna B. está realizando a mesma atividade que a aluna E. no excerto 02. Neste caso, o que se observa é que a tentativa da segunda professora de resolver "logicamente" o impasse encontrado pela aluna não leva a lugar nenhum: mesmo respondendo corretamente a cada etapa das perguntas sobre a família silábica da letra "N", a aluna falha em articulá-los para concluir qual seria a resposta à sua dificuldade. Trata-se, é claro, de um exemplo do desencontro entre o que o professor supõe ser o melhor percurso para elucidar um problema - decompô-lo em etapas: a "tarefa de ensinar”, que designa a si mesmo em seu papel e a maneira como a aluna B. provavelmente chegou a decidir, corretamente, como grafar as duas primeiras sílabas da palavra que não consegue completar.

Uma das maneiras de tentar enfrentar situações como essas no âmbito do projeto é por meio de atendimentos individuais, nos quais se busca trabalhar sobre as dificuldades da criança que, em sala, impedem que ela acompanhe o restante da turma e muitas vezes, por conta do andamento das atividades designadas para o grupo, ficam sem um tratamento específico.

Os exemplos a seguir ilustram uma sequência de situações vivenciadas pela mesma aluna B. nas atividades em sala de aula e posteriormente nos atendimentos individuais. Os excertos mostram que em sala B. se mantém calada, respondendo às perguntas da professora depois que o resto da turma respondeu. Quando indagada diretamente, a primeira resposta que ouvimos quase sempre é “não sei”.

(04) [...] Já B., a professora perguntava, e ela não respondia ou dizia que não sabia, repetia as sílabas junto com a professora, mas não sabia dizer que letras formavam aquela sílaba. Quando chegou na palavra "buzina”, ela escreveu até "buzi” e não conseguia fazer o "na", a professora comparou com a última sílaba de "sino", falando a ela os pares silábicos (na, ne, ni, no, nu), mas quando perguntava qual era a letra que ela devia colocar no fim 
da palavra ela só ficava repetindo a sílaba "na”, mas não respondia.

Nessa situação, observa-se que a aluna B. tem dificuldade em escrever uma sílaba da “família do N". No diagnóstico bimestral feito para cada aluno da turma, consta que

(05) [...] a aluna sente dificuldade em juntar as sílabas em uma palavra. Ela identifica sílabas como pedaços isolados, portanto quando a ajudamos a escrever, é necessário fazê-la reler o que escreveu para que ela perceba a formação da palavra. Fazendo isto, ela lê pedaço por pedaço e falamos para ela ir lendo mais rápido, assim ela passa a reconhecer a palavra.

O pressuposto que levou a equipe do projeto a trabalhar sistematicamente com atendimentos individuais é que o momento em que se tira uma criança da sala de aula por um determinado período permite a construção de novos vínculos do sujeito com o outro. Nesse sentido, o estranhamento inicial das crianças e a excepcionalidade da situação podem ter um efeito positivo, que é a suspensão das imagens às quais o comportamento da criança no grupo pode estar condicionado e a instauração de algumas interrogações no lugar de estereótipos que a criança pode ter incorporado (“o que essa professora quer de mim agora?”, "por que me tiraram da classe?”, “o que vamos fazer aqui?” etc.). Foi observado, nos atendimentos individuais com a aluna B., por exemplo, que houve uma mudança no comportamento dela, que pareceu se sentir mais livre para se arriscar a dizer o que sabia. O trecho a seguir descreve o desempenho dela durante uma das sessões de atendimento:

(06) B. conseguiu memorizar a parlenda "hoje é domingo...”.
Rébus (figuras + sílabas): formou sozinha "cabide”, "boboca”, "babá” e “coca”. Ela queria formar "escola", mas não tinha uma figura que começasse com LA. Perguntei que desenho precisaria para ter o LA, ela disse "laço".

B. recontou a história do Saci que lhe contei na hora.

No momento do atendimento, aos poucos a aluna pareceu à vontade, tomando iniciativas que não eram tomadas em sala de aula. Em momento nenhum do atendimento foi registrado que a aluna tenha afirmado não saber fazer alguma atividade, como era de costume em sala. Além disso, é possível notar que, ao contrário do que o diagnóstico apontava, a aluna consegue formar palavras a partir da junção de sílabas - embora o faça por meio de figuras (usando o princípio do rébus), e não das sílabas escritas alfabeticamente.

A partir desse tipo de registro tem-se elaborado outras formas de levar a criança à solução das dificuldades que encontra. Neste caso, tudo indica que o impasse encontrado por B. ao tentar escrever as palavras "novelo" e "buzina” está relacionado à tentativa de solucioná-lo pelo "método da silabação", particularmente com uma litania que parece não fazer sentido para a criança: " $\mathrm{N}$ com $\mathrm{O}$ faz NO”. A própria repetição desse “mantra”, entoado com a convicção de que ali está uma resposta que a aluna não consegue encontrar, parece ajudar a mantê-la estacionada diante do mesmo problema, embora sua capacidade de resolvê-lo pelo rébus sugira outras soluções que poderiam ser experimentadas. De modo geral, muitas crianças envolvidas no projeto têm conseguido avançar mais rapidamente na escrita e leitura de palavras em rébus do que na escrita e leitura das mesmas palavras grafadas alfabeticamente, o que tem nos levado a elaborar atividades que utilizam 
o princípio da “escrita por imagens” como transição de uma representação da língua por grafismos para uma representação convencional (alfabética), com a gradual inserção da forma alfabética de grafia das sílabas junto à figuras e, posteriormente, a retirada das figuras.

\section{Considerações finais}

Considerando os resultados preliminares apresentados anteriormente, a primeira consideração a fazer diz respeito à complexidade da relação professor-aluno ou, especialmente, de acordo com os termos apresentados por Smolka (2004), da distinção entre relação de ensino e tarefa de ensinar. De um lado, as teorias de linha cognitivista parecem contribuir de forma importante para a compreensão de que a função do professor não é a de transmitir o conhecimento escolar, mas de criar condições para que outro sujeito possa reconstruí-lo. A percepção de que algo que a criança aprende quase sempre é diferente do que foi ensinado parece elucidar, em parte, o desencontro incontornável entre o que se supõe estar ensinando e o que é efetivamente aprendido. No entanto, parece que esse desencontro não diz respeito apenas à diferença entre os "esquemas de conhecimento" do professor e do aluno, mas também à opacidade da linguagem, que articula ambiguamente representações provisórias de um conhecimento "objetivo" e imagens que constituem um lugar de onde o sujeito lida com essas representações.

A segunda consideração se refere às implicações dessa premissa na forma de organização do trabalho escolar. Como vimos anteriormente, na situação em que B. foi levada ao atendimento individual houve inicialmente uma mudança de postura por parte da bolsista que a acompanhou, na tentativa de desestabelecer a ideia de que a aluna estaria sendo avaliada. Portanto, o ambiente se tornou mais ameno, facilitando não apenas a relação entre ambas, como também o próprio avanço cognitivo da aluna, que demonstrou mais desenvoltura em fazer as atividades propostas como o rébus e o reconto da história que ela mesma pediu para ouvir. Nesta mudança de comportamento identificamos o sujeito psíquico se constituindo em um novo vínculo de acordo com as relações que vão se desenvolvendo. No entanto, para que isso se torne viável como um procedimento sistemático, parece-nos fundamental a presença de dois professores em sala de aula e a própria reconstrução da função dos professores. No projeto em questão, os professores têm se alternado na condução de atividades gerais, propostas a toda a turma, e no trabalho mais ligado à escuta e ao diagnóstico individuais. O diagnóstico, por sua vez, fornece informações importantes para o feedback das atividades propostas ao grupo.

Mesmo que custosa, essa solução vem gerando bons resultados no esforço de se articular duas esferas que se mostram, ainda, bastante estanques na educação brasileira: a condução necessária de um currículo geral, regulado por uma avaliação minimamente objetiva que permita gerar indicadores aplicáveis no que diz respeito à gestão dos sistemas de educação, e um trabalho relativo às singularidades dos alunos e que garanta seu efetivo engajamento na marcha da escolarização, sem que isso tenha de vir ao custo de sua inscrição forçada em categorias prévias de desempenho, mas por meio de uma mediação que se reconstrua a cada vez e com cada aluno e ajude a reconstruir as próprias categorias de que se dispõe. 


\section{Referências}

ALLOUCH, J. Letra a letra: transcrever, traduzir, transliterar. Rio de Janeiro: Campo Matêmico, 1995.

BELINTANE, C. Vozes da escrita: em tempos de crianças e menestréis. Estilos da Clínica, vol. XIII, n. 25, p. 36-51, 2008.

. Leitura e alfabetização no Brasil: uma busca para além da polarização. Revista Educação e Pesquisa, vol. 32, n. 2, p. 261277, maio/ago. 2006.

FERREIRO, E. Reflexões sobre alfabetização. São Paulo: Cortez, 1985.

FERREIRO, E.; TEBEROSKY, A. Psicogênese da língua escrita. Porto Aletre: Artes Médicas, 1985.

FEVRIER, J. Histoire de l'écriture. Paris: Payot, 1948.

GELB, I. J. Historia de la escritura. Madrid: Alianza Editorial, 1982.

MORTATTI, M. R. L. Cartilha de alfabetização e cultura escolar: um pacto secular. Cadernos CEDES, ano XIX, n ${ }^{\circ}$ 52, nov. 2000.

HISTÓRIA DOS MÉTODOS DE ALFABETIZAÇÃO NO BRASIL, 2006. Brasília. Conferência proferida durante o Seminário "Alfabetização e letramento em debate", promovido pelo Departamento de Políticas de Educação Infantil e Ensino Fundamental da Secretaria de Educação Básica do Ministério da Educação. Brasília: Mimeo, 2006.

MOREIRA, M. A. Teorias de Aprendizagem. São Paulo: EPU, 1999.

NASIO, J.-D. Cinco lições sobre a teoria de Jacques Lacan. Rio de Janeiro: Jorge Zahar, 1993.
POMMIER, G. Naissance et renaissance de l'écriture. Paris: PUF, 1993.

SMOLKA, A. L. B. A criança na fase inicial da escrita: a alfabetização como processo discursivo. São Paulo: Cortez; Campinas: Unicamp, 2004.

Enviado em: 21/03/2013

Aceito em: 05/08/2013 